\title{
Low-input Cherry Production: A Horticultural Alternative for Marginal Highlands as a Case Study from Lebanon
}

\author{
S.N. Talhouk ${ }^{\mathbf{1}}$ and R.A. Chahine \\ Department of Crop Production and Protection, Faculty of Agricultural and Food Sciences, The American \\ University of Beirut, P.O. Box 11-0236, Beirut, Lebanon
}

\begin{abstract}
S. Hamadeh
Department of Animal Sciences, Faculty of Agricultural and Food Sciences, The American University of Beirut, P.O. Box 11-0236, Beirut, Lebanon
\end{abstract}

\author{
B.C. Hamdar \\ Department of Agriculture Economics and Development, Faculty of Agricultural and Food Sciences, The \\ American University of Beirut, P.O. Box 11-0236, Beirut, Lebanon
}

\author{
R. Baalbaki \\ Department of Crop Production and Protection, Faculty of Agricultural and Food Sciences, The American \\ University of Beirut, P.O. Box 11-0236, Beirut, Lebanon
}

\begin{abstract}
The marginal lands of West Asia and North Africa (WANA region) are characterized by a fragile and limited natural resource base, fluctuating environmental conditions, and low production potential. These areas contain some of the poorest farmers facing the harshest conditions in the WANA region (Byerlee and Morris, 1993; International Center for Agriculture Research in the Dry Areas, 1991, 1992, 1993). The agricultural systems that have been developed to deal with such lands rely mainly on the production of low-intensity and lowproductivity agronomic crops that are well adapted to their environment (International Center for Agriculture Research in the Dry Areas, 1991, 1992, 1993).

Marginal lands constitute a large part of the total area of Lebanon. During the first half of this century, villages on the marginal slopes of the Anti-Lebanon mountains survived in a traditional agropastoral economy based on small-scale farming and seasonal migration (Hamadeh et al., 1993). However, basic cultural and economic changes during the past 25 years (e.g., the development of a market-oriented economy), major decreases in purchasing power, and a marked migration of villagers to cities have had a drastic impact on the use of the natural resource base (Hamadeh et al., 1993). Future productive use of these natural resources and the long-term viability of agriculture in the area are at risk, and sustabinability is at stake.
\end{abstract}

\section{DESCRIPTION OF THE AREA STUDIED}

This study focused on a remote Lebanese town that depends on surrounding marginal highlands for its agriculture. Irsal is a village

Received for publication 13 July 1995 . Accepted for publication 21 Nov. 1995. The cost of publishing this paper was defrayed in part by the payment of page charges. Under postal regulations, this paper therefore must be hereby marked advertisement solely to indicate this fact.

${ }^{1}$ To whom reprint requests should be addressed. located on the western slopes of the AntiLebanon mountains, at an elevation of 1450 $\mathrm{m}$. Average rainfall in the highlands, mostly in the form of snow, is $300 \mathrm{~mm}$. The population of Irsal is estimated at 30,000. Less than $10 \%$ of the population migrates as seasonal herders or workers. Agriculture is the main occupation and source of income in Irsal (Hamadeh et al., 1993).

Agriculture in the highlands of Irsal is undergoing a transition from the traditional agropastoral system to a nonirrigated fruit production system (Hamadeh et al., 1993). Fifty years ago, half of the 10,000 ha of arable lands of the Irsali highlands produced grains amounting to $2400 \mathrm{t}$ ( 0.4 tons/ha) (Hamadeh et al., 1993). Today the main nonirrigated agronomic crops grown by Irsali farmers consist of wheat (Triticum aestivum L.), barley (Hordeum vulgare L.), and chickpea (Cicer arietinum $\mathrm{L}$.). There is now, however, a sharp decline in cereal production, being replaced, through the farmer's own initiative, with tree fruit production, mainly cherries (Prunus avium L.) and apricots (Prunus armeniaca L.).

Due to its remote location, Irsal was deprived of the agricultural development advances usually occurring in villages near major roads. This isolation led Irsali farmers to try farming alternatives requiring few offfarm inputs. Despite the remoteness of the town and the resulting marketing problems, they found that fruit crop production was more profitable than the production of the traditional agronomic crops.

The purpose of our study was to test the viability of this new low-input cherry production system by comparing its results with those obtained from the traditional intensive cherry production system currently prevailing in the agricultural lands of the Bekaa plain.

\section{ORGANIZATION OF THE STUDY}

Cherry orchards in the Bekaa Plain were selected randomly to represent the high-input production system. The selected orchards were located at altitudes ranging between 650 and
$1100 \mathrm{~m}$. A review of local information on cultural practices in the selected areas of the Bekaa Plain, as well as Irsal, was used to design a questionnaire composed of closedended questions. It was pretested and translated into Arabic before being administered as personal interviews with the growers. The number of interviewees included 89 cherry growers from the Bekaa area and 69 from Irsal.

Comparisons between the two production systems were drawn for small $(<0.6 \mathrm{ha})$, medium (0.6-1.5 ha), and large ( $>1.5$ ha) orchards (Table 1).

To assess the annual cost of production per hectare, total amounts were requested for each of the following expenditures: tillage, seedlings, chemicals (including fertilizers and pesticides), manure, labor (including family labor at locally prevailing rates), fuel, weeding, pruning, transportation, irrigation, and harvesting. The total cost of production per hectare for each represented orchard size for both areas was then calculated (Table 2). The revenue from the orchards was calculated from the total quantity of cherries harvested.

\section{DESCRIPTION OF THE PRODUCTION SYSTEMS}

The close similarities in average orchard sizes in the two areas had not been expected, because the size of arable lands in the highlands of Irsal is greater than those of the Bekaa,

Table 1. Orchard sizes in Bekaa and Irsal.

\begin{tabular}{llrrl}
\hline \hline $\begin{array}{l}\text { Production } \\
\text { area }\end{array}$ & $\begin{array}{l}\text { Size } \\
\text { range } \\
(\text { ha) }\end{array}$ & $\mathrm{N}$ & $\%$ & $\begin{array}{l}\text { Avg } \\
\text { size } \\
\text { (ha) }\end{array}$ \\
\hline Bekaa & $<0.6$ & 23 & 26 & 0.3 \\
& $0.6-1.5$ & 35 & 39 & 1.0 \\
& $>1.5$ & 31 & 35 & 2.3 \\
& Total & 89 & 100 & --- \\
Irsal & $<0.6$ & 16 & 23 & 0.3 \\
& $0.6-1.5$ & 30 & 44 & 1.3 \\
& $>1.5$ & 23 & 33 & 2.0 \\
& Total & 69 & 100 & --- \\
\hline
\end{tabular}

${ }^{\mathrm{z}}$ Small, medium, and large, respectively. 
thus allowing for the establishment of larger orchards. However, those lands, which in the past had been leased for grazing for the benefit of family groups, had been split up and fragmented as the population in the area increased and the agricultural system was changing from the earlier agropastoral mode to the newer fruit production system. Unlike orchards in the Bekaa area, which are located near the growers' houses (95\% less than $5 \mathrm{~km}$ ), Irsali orchards are located far from the villagers' houses. Most of the cherry growers' lands $(70 \%)$ are located $11-20 \mathrm{~km}$ from their houses, and $8 \%$ are located more than $30 \mathrm{~km}$ away. Moreover, unlike most growers in the Bekaa who use machinery to reach their orchards (80\%), the majority of Irsalis rely on animal transport $(86 \%)$. As a result, the whole family generally moves into a "summer" house at the orchard site and participates in the harvest.

Tillage operations in Irsal are powered by animals (93\%), which are shared between growers, while in the Bekaa the majority use machinery $(87 \%)$, which is usually rented.

\section{COMPARATIVE ANALYSIS OF THE SYSTEMS}

The total costs of production per hectare were estimated for both areas using 1993 prices (Table 2). The absence of irrigation, chemical use, pruning, weeding, fuel, electricity use, and machinery maintenance in Irsali orchards contributed towards lower operational costs in Irsal than in the Bekaa area.

Cherry production in Irsal is exclusively rainfed $(100 \%)$ while the majority of orchards in the Bekaa are irrigated (81\%). Most growers in Bekaa (95\%) use commercial chemicals for fertilization and pest control. The growers in Irsal (99\%) do not. The reasons given by Irsali growers for this lack of use include cost, lack of knowledge, and lack of access to chemicals due to remoteness of orchards. Unlike growers in the Bekaa area, the Irsalis do not prune their trees nor do they weed their orchards. According to Irsali growers, the lack of pruning is the result of lack of knowledge about cultural practices of this recently introduced crop. Weeding is not practiced nor is it needed in Irsali orchards, which are rainfed and established on lands where native bushes and occasional trees prevail.

Transportation of the harvested product to market is a major cost for Irsali growers, almost double that for those from the Bekaa having medium- or large-sized orchards. Due to the remoteness of their orchards and lack of roads, Irsali cherry growers are completely dependent on middlemen, other villagers who own pickup trucks, to transport their produce to market. The price received for the fruit at the farm gate is determined by bargaining between the Irsali fruit growers and truckers. Because they can reach their wholesale markets without the services of middlemen, Bekaa growers have more control over selling prices and transportation costs.

The cherry yield per tree is almost identical in the two areas, in spite of the differences in production methods ( $40 \mathrm{vs} .36 \mathrm{~kg} /$ tree in Bekaa and Irsal, respectively). Total fruit yields per hectare, however, were greater in Bekaa than in Irsal, regardless of orchard size. This differ-

Table 2. Total production costs per hectare of cherry orchards in Bekaa and Irsal for $1993 .{ }^{2}$

\begin{tabular}{|c|c|c|c|c|c|c|}
\hline \multirow{3}{*}{$\begin{array}{l}\text { Production } \\
\text { inputs }\end{array}$} & \multicolumn{6}{|c|}{ Orchard size } \\
\hline & \multicolumn{2}{|c|}{ Small } & \multicolumn{2}{|c|}{ Medium } & \multicolumn{2}{|c|}{ Large } \\
\hline & Bekaa & Irsal & Bekaa & Irsal & Bekaa & Irsal \\
\hline Tillage & 490 & 180 & 610 & 220 & 1200 & 360 \\
\hline Transplanting & 230 & 160 & 230 & 160 & 230 & 160 \\
\hline Terraces & 0 & 0 & 0 & 0 & 80 & 90 \\
\hline Irrigation & 670 & 0 & 200 & 0 & 150 & 0 \\
\hline Harvesting & 2300 & 1610 & 2300 & 1610 & 2300 & 1610 \\
\hline Chemicals & 1000 & 0 & 1000 & 0 & 870 & 0 \\
\hline Manure & 310 & 100 & 120 & 40 & 160 & 60 \\
\hline Pruning & 190 & 0 & 180 & 0 & 300 & 0 \\
\hline Weeding & 310 & 0 & 120 & 0 & 150 & 0 \\
\hline Transportation & 770 & 560 & 350 & 600 & 270 & 590 \\
\hline Fuel & 1720 & 0 & 1070 & 0 & 520 & 0 \\
\hline Electricity & 0 & 0 & 0 & 0 & 190 & 0 \\
\hline Miscellaneous & 380 & 380 & 170 & 0 & 200 & 0 \\
\hline Machinery & & & & & & \\
\hline maintenance & 190 & 0 & 60 & 0 & 50 & 0 \\
\hline Total & 8560 & 2990 & 6410 & 2630 & 6670 & 2870 \\
\hline
\end{tabular}

${ }^{2}$ Values are 1993 prices in U.S. dollars; rounded to nearest $\$ 10$.

Table 3. Total net revenue per hectare from cherry orchards in Bekaa and Irsal for 1993. ${ }^{2}$

\begin{tabular}{|c|c|c|c|c|c|c|}
\hline \multirow[b]{3}{*}{ Variable } & \multicolumn{6}{|c|}{ Size of orchard } \\
\hline & \multicolumn{2}{|c|}{ Small } & \multicolumn{2}{|c|}{ Medium } & \multicolumn{2}{|c|}{ Large } \\
\hline & Bekaa & Irsal & Bekaa & Irsal & Bekaa & Irsal \\
\hline Total production cost/ha & 8,560 & 3,000 & 6,380 & 2,630 & 6,670 & 2,860 \\
\hline Total revenue/ha & 9,600 & 6,750 & 9,050 & 7,140 & 12,410 & 7,140 \\
\hline Net revenue/ha & 1,040 & 3,750 & 2,670 & 4,510 & 5,740 & 4,280 \\
\hline
\end{tabular}

${ }^{\mathrm{z}}$ Values are 1993 prices in U.S. dollars, rounded to the nearest $\$ 10$.

ence was due primarily to more trees per hectare in Bekaa (400 trees/ha) than in Irsal (280 trees/ha). We thought that the similarity in yield between the two production systems might be due to the fact that the study was performed during a season of good water availability in Irsal; if true, then results might be different under less favorable weather conditions. Further study of this matter through another closed-ended survey of the Irsal growers, however, indicated that yields had been similar or higher ( $83 \%$ of respondents, $\mathrm{N}=75$ ) for the past 5 years than during the test year. Unfavorable environmental factors had resulted in decreased productivity only once or twice during those 5 years $(75 \%$ of respondents); but the damage had been caused by snow (breakage of branches) and late spring frosts rather than summer drought.

Growers in Irsal and the Bekaa area use the same local cherry varieties grafted on Mahaleb seedling rootstock. Growers in Irsal have one potential advantage over the Bekaa producers in that their time of bloom and therefore harvest is about 1 month later. In the Bekaa area, $60 \%$ of the orchards flower in March and those remaining in April, while only $28 \%$ of the orchards in Irsal flower in April and those remaining in May. The later crop makes Irsali fruit available at a time of low national production, which permits them to sell a highly desired crop with little local competition. This potential advantage, however, is partially offset by the fact that their farm gate values are just about the same as those received by the growers in Bekaa, whose harvests arrive at a time of peak competition (U.S. $\$ 0.65 / \mathrm{kg}$ in Bekaa, U.S. $\$ 0.70 / \mathrm{kg}$ in Irsal). The longer distances between their area of production and their markets did have a negative impact on the Irsali growers.

Despite the lower gross revenue/hectare in small- and medium-sized orchards in Irsal, Irsali growers had a higher net revenue than their counterparts in Bekaa because of their lower level of inputs (Table 3). This was not the case, however, with large orchards, where profits were higher in the Bekaa area than in Irsal. Net profit in Bekaa increased with increasing orchard size; in Irsal net profit was about the same regardless of orchard size.

\section{CONCLUSIONS}

A sustainable system is defined as being one that is profitable without a significant dependence on off-farm inputs, while at the same time being environmentally sound (Ikerd, 1990). This study suggests that low-input production of fruit trees adapted to marginal environments deserves further consideration as a potentially sustainable agricultural production alternative.

Although currently feasible, the sustainability of the low-input production system in Irsal depends on many factors that need further investigation. The movement from the previous agropastoral system to horticultural fruit tree production and the resulting changes in cultural practices might affect soil erosion in the area. The lack of fertilization might lead 
to mineral depletion, resulting in decreased yields and tree growth. The rapid increase in the number of orchards in the area $(65 \%$ of cherry orchards are less than 10 years old) may eventually lead to the introduction of pests and diseases exotic to the area. A recent preliminary assessment of tree health in Irsali orchards has unveiled developing problems. Infestations of the flat-headed borer (Capnodis tenebrionis L.) have caused major tree losses in a few orchards. This species is a serious pest of cherry and apricot grown in dry climates (Viggiani, 1991); it weakens and even kills the infested trees. Other identified pests in those infested orchards included the shot hole borer (Ruguloscolytus rugulosis Retz.) and the cherry slug worm (Caliroa cerasi Retz.). To sustain a feasible fruit production system in the marginal lands of Irsal, research is needed to develop a low-input integrated pest management program aimed at improving tree vitality. Meanwhile, Irsali farmers, on their own initiative, have already started spending increasing amounts of money to spray their trees with various chemicals in an attempt to control these problems.

\section{Literature Cited}

Byerlee, D. and M. Morris. 1993. Research for marginal environments: Are we underinvested? Food Policy. Oct.: 381-391.
Hamadeh, S.K., H. Seeden, S.N. Talhouk, R. Baalbaki, and R. Zreik. 1993. Changes in traditional agropastoral systems: A Lebanese case study. International Center for Agriculture Research in the Dry Areas Dryland Management Project Workshop. Allepo, Syria. (In press.)

International Center for Agriculture Research in the Dry Areas. 1991. Annual report. Aleppo, Syria. International Center for Agriculture Research in the Dry Areas. 1992. Annual report. Aleppo, Syria. International Center for Agriculture Research in the Dry Areas. 1993. Annual report. Aleppo, Syria.

Ikerd, J.E. 1990. Agriculture's search for sustainability and profitability. J. Soil Water Conservation 45:18-23.

Viggianni, G. 1991. Pests of apricot. Acta Hort. 293:481-486. 